\title{
LA CIUDAD EN DISPUTA. DESARROLLO URBANO Y DESARROLLO ECONÓMICO EN SAN CARLOS DE BARILOCHE
}

\author{
THE CITY IN DISPUTE. ECONOMY AND TERRITORY \\ IN SAN CARLOS DE BARILOCHE
}

\author{
Tomás Guevara* y Paula Núñez*
}

\begin{abstract}
Este artículo problematiza las vinculaciones entre la política urbana y la conformación territorial de la ciudad de San Carlos de Bariloche, a partir del funcionamiento del mercado de tierras y la disputa por la apropiación y uso del espacio urbano. En este sentido, el trabajo aporta una reflexión en torno a la relación entre los modelos de desarrollo económico y urbano de las ciudades contemporáneas, relación que muchas veces se pierde de vista en la literatura, privilegiando uno u otro componente. Para ello se realiza un estudio de caso del actual barrio 10 de Diciembre, mediante fuentes documentales y entrevistas en profundidad. Este barrio aparece como un caso paradigmático de disputa de un área de la ciudad a la convergencia entre los intereses económicos del sector privado y un planeamiento urbano completamente funcional a dichos intereses.

En este marco, el barrio 10 de Diciembre ha sido una de las áreas con mayores intentos de relocalización poblacional compulsiva, fundamentados en presiones inmobiliarias y la idea de ciudad que subyace a los diferentes instrumentos de planificación urbana, que reservaban las tierras periféricas para los sectores populares. La historia de este barrio resume muchas de las tensiones, históricas y coyunturales, que estructuraron a la ciudad y que parecen repetirse en otras localidades vinculadas a la explotación turística.

Palabras claves: Urbanización, política urbana, apropiación del espacio.
\end{abstract}

This article delves into the linkages between entrepreneurial interests related to real estate and tourism and urban policy in the city of San Carlos de Bariloche, through the dynamics of the land market and the dispute over the appropriation and use of urban space. In this sense, the work provides a reflection on the relationship between the models of economic and urban development of contemporary cities, relationship that is often lost of sight in the literature. To do this, a case study of the Barrio 10 de Diciembre is carried forward, through documentary sources and interviews. This area appears as a paradigmatic case of a disputed area of the city to the convergence between the economic interests of the private sector and a urban planning functional to such interests. In this framework, the Barrio 10 de Diciembre has been one of the areas with more compulsive attempts of eradication, because of real estate pressures and the city image embodied in the different urban planning instruments, which reserve peripheral land for popular sectors. The history of this neighborhood summarizes many of the tensions, historical and contextual, which structured the city and which seem to be replicated in other cities linked to the tourist exploitation.

Key words: Urbanization, Urban policies, urban space appropriation.

\section{Introducción}

Este artículo intenta comprender el vínculo entre la política urbana y la conformación territorial de la ciudad de San Carlos de Bariloche, a partir del funcionamiento del mercado de tierras y la disputa por la apropiación y uso del espacio urbano. En este sentido, el trabajo aporta una reflexión en torno a la relación entre los modelos de desarrollo económico y urbano de las ciudades contemporáneas, relación que muchas veces se pierde de vista en la literatura, privilegiando uno u otro componente. Para ello, se realiza un estudio de caso del actual barrio 10 de Diciembre, mediante fuentes documentales y entrevistas en profundidad. Este barrio aparece como un caso paradigmático de disputa de un área de la ciudad a la convergencia entre los intereses económicos del sector privado y un planeamiento urbano funcional a dichos intereses. La expansión de lo que se conoce como el urbanismo neoliberal (Smith, 2002), que orienta los procesos de producción del hábitat y el territorio por la lógica privada (Pírez, 2006), hace que este tipo de conflictos por la apropiación del espacio urbano sean muy comunes en las ciudades contemporáneas (Guevara, 2010 y 2013) ${ }^{1}$.

* Universidad Nacional de Río Negro, San Carlos de Bariloche, Argentina. Consejo Nacional de Investigaciones Científicas y Técnicas (Conicet). Correos electrónicos: tguevara@unrn.edu.ar; pnunez@unrn.edu.ar 
Bariloche es una ciudad turística que reconoce sus mayores atractivos en el paisaje natural que la circunda. El crecimiento de la ciudad se ha planificado en varias ocasiones tomando como eje de interés a esta actividad económica (Lolich 2010), pero a pesar de las recurrentes planificaciones, las tensiones de la expansión de la población no termina de ser respondida adecuadamente desde la política pública. Esta incapacidad se reconoce, entre muchos otros elementos, en la insuficiencia en la dotación de servicios para una proporción elevada de la población, así como en el crecimiento en las dificultades de acceso a la tierra para vivienda (Abalerón, 2005). Esto último se puede observar en el funcionamiento del mercado de tierras de la ciudad, caracterizado por un alto componente especulativo y por una arraigada cultura patrimonialista, que privilegia el interés individual del propietario en aras de promover la inversión, el crecimiento económico y la creación de empleo, sin considerar dinámicas de crecimiento que involucren a una pluralidad más compleja de sectores sociales. Así, las tensiones y contradicciones del desarrollo no fueron problematizadas y abordadas de manera cabal, y en consecuencia apareció como un recurso reiterado del gobierno local la identificación de determinados sectores sociales vulnerables como obstáculos al desarrollo (Núñez y Guevara, 2014).

En las páginas que siguen se buscará indagar acerca de la relación entre los modelos de desarrollo económico y desarrollo urbano propuestos para la ciudad de Bariloche, a partir de reconstruir la historia de conformación de un barrio popular: el barrio 10 de Diciembre (ver Figura 1).

Elegimos este espacio porque resume muchas de las tensiones que afectan a la ciudad en su conjunto, siendo una de las áreas con mayores intentos de relocalización poblacional compulsiva, que se impulsaron desde las esferas de gobierno en consonancia con las presiones de los intereses del sector privado. Esta definición era consonante con cierta idea o modelo de ciudad que subyace tanto a los instrumentos de planificación como a las prácticas e iniciativas concretas del gobierno local, que definen a las tierras periféricas como el lugar de localización de los sectores populares. En este sentido, la localización del barrio 10 de Diciembre es un desafío abierto a esta concepción de ciudad guiada por la necesidad de presentar cierta "imagen idílica" al turismo y configura lo que Duhau y Giglia caracterizan como un conflicto urbano, es decir, aquellas situaciones que ponen en disputa el conjunto de normas y reglas, tanto formales como convencionales, a las que recurren los habitantes de la ciudad en el desarrollo de las prácticas relacionadas con los usos y las formas de apropiación de los espacios y bienes públicos o de uso colectivo (2004).

La metodología utilizada en la reconstrucción del estudio de casos es el análisis documental y la

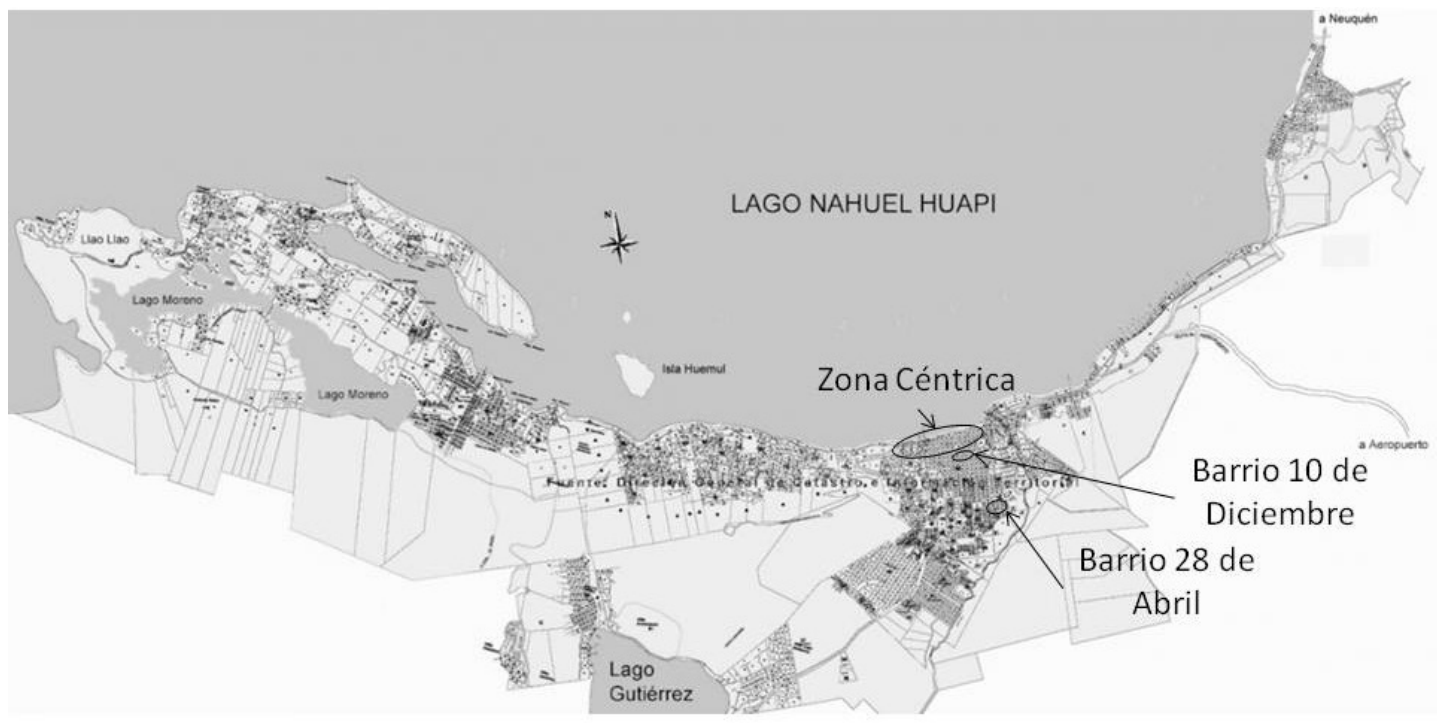

Figura 1: Esquema de la ubicación del barrio 10 de Diciembre y el barrio 28 de Abril.

Fuente: Elaboración propia sobre mapa de catastro. 
historia oral (Schwarzstein, 2001; Plá, 2001). Los documentos que nos ayudan en nuestro recorrido son fuentes documentales parcialmente indagadas, entre las que se cuentan los repositorios editados como los planes urbanos, las ordenanzas municipales, los reservorios periodísticos, los datos censales, las reglamentaciones municipales. Este corpus se complementará con publicaciones internas del barrio inéditas (boletines barriales realizados por la Junta Vecinal y por la Comisión de Tierras), así como una serie de entrevistas a vecinos y vecinas pertenecientes a organizaciones sociales de base ${ }^{2}$. La metodología de la historia oral encuentra su justificación no solo en posibilitar la expresión y la perspectiva de determinados sectores sociales que no suelen participar activamente de los relatos historiográficos, sino que también se justifica porque el proceso se resistencia barrial que aquí se reconstruye está completamente ausente de esos relatos historiográficos, omisión que es de por sí una toma de posición fundamental.

El trabajo se organiza en tres secciones. La primera, analiza a escala de la ciudad la dinámica del mercado de tierras y su relación con el modelo de desarrollo centrado en el turismo que se vuelve hegemónico a partir de mediados del siglo XX. La segunda, reconstruye el proceso de urbanización del barrio estudiado y su inserción urbana en la ciudad de San Carlos de Bariloche. La tercera, analiza la construcción de marcas sociales vinculadas a grupos sociales vulnerables y su inserción en una matriz de pensamiento que los responsabiliza como los obstáculos para el desarrollo económico y social exitoso de la localidad. El último apartado, y a modo de conclusiones, reflexiona sobre la experiencia de urbanización del barrio 10 de Diciembre y los desafíos aún abiertos en la generación de procesos de integración urbana y social más amplios.

\section{Las Tierras de San Carlos de Bariloche y el desarrollo del turismo}

Desde la década de 1930 y 1940 en Bariloche se fraccionaron en gran cantidad tierras originalmente destinadas a lotes pastoriles ${ }^{3}$ (Vallmitjana 1989) para ser incorporados al ejido urbano en expansión. Así, amplios sectores fueron subdivididos sin prever la consolidación urbanística, el trazado de las calles ni la dotación mínima de infraestructura de servicios ${ }^{4}$. Actualmente San Carlos de Bariloche constituye uno de los ejidos urbanos más extensos y menos densos, configurando un modelo de desarrollo urbano poco sustentable (Ainstein, Kralich, Villadeamigo y Guevara 2012).

Esto fue posible por la vigencia de una normativa urbana muy laxa en términos de subdivisión y uso, que replica en una escala mayor la falta de una planificación rectora. Abalerón (2001) estima más de tres mil novecientas hectáreas loteadas en los años 40, principalmente en áreas boscosas. Este loteo masivo fue propiciado por la Administración de Parques Nacionales, primer organismo con incumbencia territorial en la zona, para financiar las obras de infraestructura que modernizaran la aldea de montaña para convertirla en un destino turístico de elite. El informe de análisis y diagnóstico del Plan de Ordenamiento Territorial (1977), realizado por la Arq. Odilia Suárez, calcula entre 1934 y 1960 un ritmo anual de parcelamientos suburbanos de ciento noventa y seis hectáreas por año, es decir, alrededor de cuatro mil novecientas hectáreas. Entre 1960 y 1977 el proceso se frena pero no se termina, manteniéndose a un ritmo de parcelamientos de veinticinco hectáreas por año, totalizando cuatrocientas cincuenta y cinco hectáreas, que lejos de resolver los problemas habitacionales alimentaron una iniciativa de especulación inmobiliaria cada vez más voraz.

Todo el período estuvo atravesado por recurrentes normativas que buscaban controlar y condicionar los parcelamientos a la provisión de infraestructura y equipamiento, como el Reglamento de Subdivisiones de 1965 y su posterior modificación o flexibilización en virtud de las presiones vinculadas a los intereses que operaban en el mercado inmobiliario. Ya el estudio de Hardoy para el plan físico para San Carlos de Bariloche de 1964 diagnosticaba que gran parte de los loteos se producían por especulación y no por genuina necesidad. En 1978 se sancionó un Plan Director que impedía realizar nuevos loteos, sin embargo el crecimiento urbano en extensión de Bariloche continuó de forma sostenida durante las últimas décadas, avanzando sobre las tierras rurales periurbanas.

Desde la extensión del ejido municipal sancionada por la Ley Luelmo 14.487 de 1958, en donde todas las tierras fiscales pasaban a control de la Municipalidad, se reconoció que la extensión de los servicios básicos resultaba muy cara y problemática, cuando no directamente inviable. Esta dinámica de manejo parcial y errático es una marca de la gestión urbana de la ciudad que permanece 
hasta la actualidad (Núñez 2008). Así, la falta de consideración, el silenciamiento y el desconocimiento respecto de las dinámicas poblacionales de los diferentes barrios impactan decididamente en el desarrollo local, incluso llegando a amenazar la sustentabilidad de los servicios del turismo.

Según Abaleron (1995), desde la década de 1980 se lotearon más de seiscientas hectáreas adicionales. Como resultado, prácticamente la totalidad del ejido urbanizable está loteado, pese a que su materialización y consolidación urbana está todavía pendiente. Si bien no se cuenta con datos recientes, se puede observar que la ciudad continuó extendiéndose y completándose hacia el sur y este en los últimos años con un alto grado de informalidad. Asimismo, emergieron nuevas tipologías habitacionales como las urbanizaciones cerradas, donde se localizaron sectores de ingresos medios-altos ${ }^{5}$, introduciendo heterogeneidad en la trama urbana.

Se puede afirmar que este manejo improvisado de las tierras y la exacerbación de los intereses empresariales inmobiliarios estuvieron directamente vinculados al desarrollo de la principal actividad económica de la localidad, el turismo. Desde la década de 1960 se reconocía a esta actividad como problemática por estar fuera de las consideraciones y planificaciones de actividades económicas de nivel nacional (Fanjul 1964) y, por ende, carente de una organización y proyección clara. Esto redundaba, una vez más, en la falta de planificación adecuada para el desarrollo de una ciudad basada en dicha actividad. Esta situación generó que la dinámica inmobiliaria y sus precios estén determinados por la demanda vinculada a una errática demanda exógena -vinculada a usos destinados a la población visitante, como hoteles, cabañas, restaurantes, etc.- ampliándose cada vez más la brecha con los ingresos de la población local.

Las restricciones en la provisión e infraestructura, por su parte, operaron impulsando todavía más al alza los precios del suelo (Jaramillo 2009). Es interesante reflexionar acerca de que esta falta de planificación adecuada está terminando por afectar el sector turístico como tal. La ciudad aparece atractiva casi exclusivamente en un espacio particular, el circuito Centro Cívico - Calle Mitre - Catedral. Hay un descuido en la mejora de otras áreas atractivas, que carecen de servicios equivalentes o, incluso, que tienen restricciones en términos de accesibilidad ${ }^{6}$. Asimismo, infraestructuras ya establecidas se han visto desmanteladas ${ }^{7}$ y puntos de atractivo han sido cooptados por emprendimientos que no tienen un suficiente cuidado del entorno natural, afectando la sustentabilidad del recurso ${ }^{8}$. De modo que en este crecimiento caótico se puede reconocer tanto la base de una integración desigual al proyecto de desarrollo económico hegemónico como el debilitamiento de la sustentabilidad a largo plazo del desarrollo de ese mismo proyecto.

\section{El Barrio 10 de Diciembre en la ciudad}

El proceso de conformación del barrio 10 de Diciembre estuvo atravesado por estas dinámicas territoriales y del mercado de suelo analizadas en el apartado anterior. Las tierras en las que se asienta el barrio tuvieron muchos destinos sucesivos, que nunca terminaron de consolidar un uso que estuviera legitimado socialmente, dando origen a una situación conflictiva que se desarrolló durante décadas. Esta situación plantea la necesidad de reflexionar acerca de las políticas urbanas en función del papel que juegan a partir de y junto con las condiciones de producción y acceso al suelo urbano, en la producción social de la ciudad. Es decir, como parte de la pugna entre diferentes clases, sectores y actores sociopolíticos por su apropiación (Rodríguez, 2006).

Originalmente las tierras habían sido destinadas a la construcción de un conjunto habitacional de la Comisión Nacional de Casas Baratas ${ }^{9}$ (ver Figura 2) para los sectores de trabajadores de la ciudad turística que se empezó a planificar en $1934^{10}$. Este proyecto habitacional se formalizó mediante un acuerdo entre la Comisión y la Dirección de Parques Nacionales en $1938^{11}$, que desde la creación del Parque Nacional Nahuel Huapi controló buena parte del crecimiento y desarrollo urbano de la localidad inmersa en el área protegida ${ }^{12}$. Los documentos de catastro registran a la mencionada Comisión como la propietaria del espacio recién a partir de 1940.

No obstante, el proyecto del conjunto habitacional nunca se materializó. Por ello, no sorprende que desde la década de 1940 empezaran a producirse los primeros asentamientos informales en el espacio, que tenía en esa época una inserción completamente periférica en la estructura urbana. Era conocido como "el barrio del tanque de agua", por la proximidad de dicho equipamiento.

La Comisión Nacional de Casas Baratas se desarma en 1945, cuando se crea bajo la gestión de Juan Domingo Perón la Administración Nacional de la Vivienda, quien afirmaba que el "organismo 


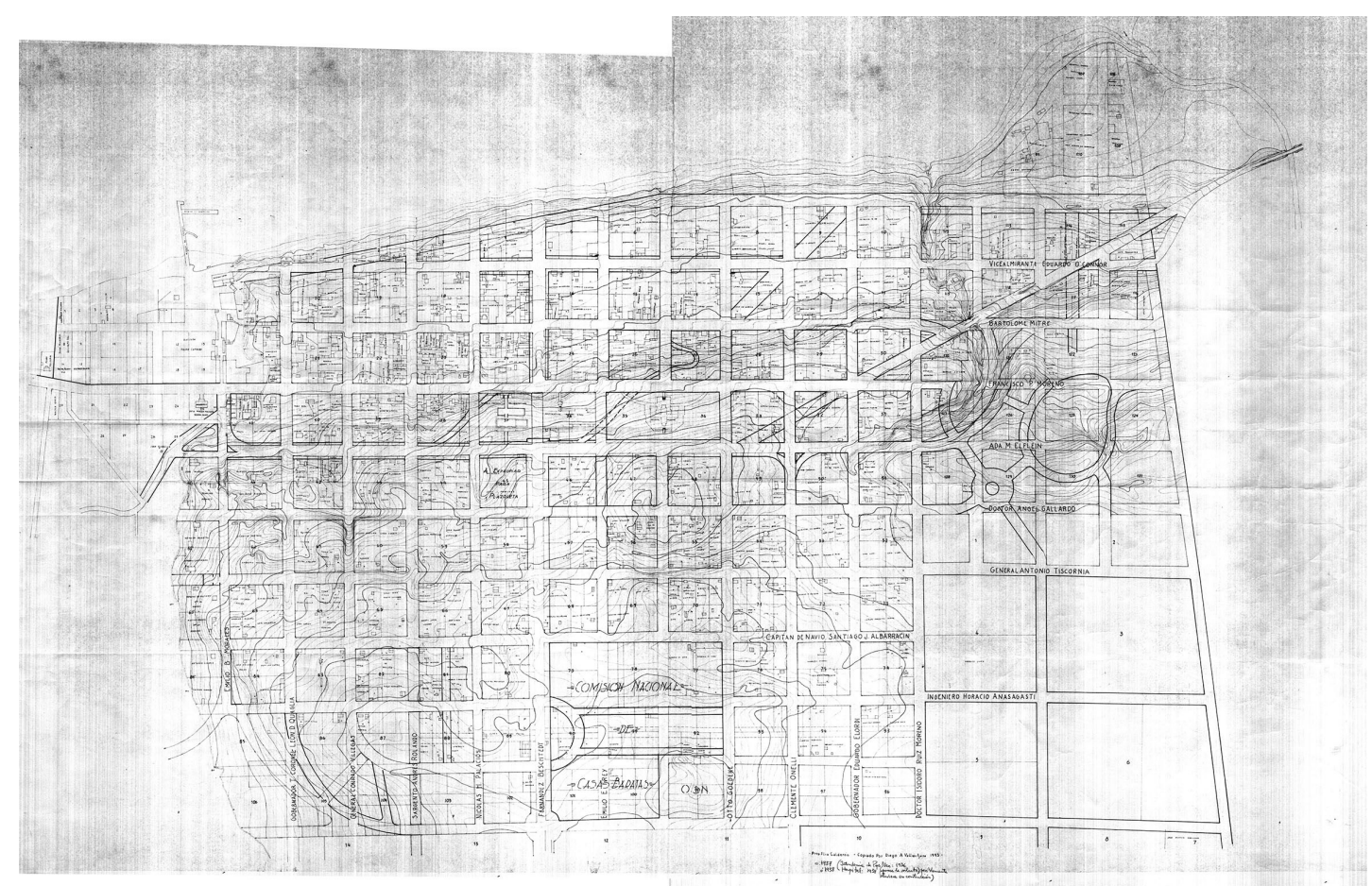

Figura 2: Terreno cedido a la Comisión Nacional de Casas Baratas, en San Carlos de Bariloche.

Fuente: Catastro Municipal. Plano 1936. Planificación de diseño urbano.

(...) tendrá a su cargo la enorme, pero nobilísima tarea de proporcionar a miles de hogares techo sano, decoroso y agradable"13. Este nuevo organismo tampoco introduce avances en la concreción del conjunto habitacional en las tierras en cuestión, que a esta altura contienen nuevos vecinos y nuevos asentamientos informales, en muchos casos en condiciones precarias.

En 1947, esta Administración pasa a depender del Banco Hipotecario Nacional, uno de los organismos más importantes en materia de políticas habitacionales por sus diferentes operatorias de créditos hipotecarios. El reconocimiento del banco como nuevo propietario recién se va a reflejar, en las ordenanzas municipales, a partir de 1968 y en los documentos de catastro a partir de 1971. No obstante, durante estos años el municipio va a tener un accionar contradictorio y errático, propiciando la instalación de nueva población en esas tierras, siempre con un carácter de tenencia precaria. Los testimonios orales recolectados dan cuenta de un gran nivel de informalidad y de discrecionalidad en el asentamiento de nuevas familias, donde las redes sociales conformadas por contactos personales y familiares jugaban un rol central (Di Virgilio, 2011) ${ }^{14}$.
Esta situación cambia a partir de la década de 1970, cuando se produce un cambio radical en la orientación del municipio que decide propiciar la llegada del primer supermercado a la ciudad (Ordenanza 11 - C - 1968) y su localización en este lugar ${ }^{15}$. La instalación del supermercado generó un gran impacto en la población que habitaba el predio. Los testimonios recolectados dan cuenta de la notable presión por parte del supermercado para remover la población asentada informalmente ${ }^{16}$.

Vale mencionar que el supermercado que se plantea para el sector estudiado fue el primero en la ciudad. De allí que modificó radicalmente la zona, al tiempo que impactó en la forma de comercialización local hasta entonces centrada en el Mercado Municipal ${ }^{17}$. La irrupción de un proyecto alternativo para las tierras, vinculado no ya al hábitat social, sino a la modernización del sector de comercialización y a la posibilidad de gentrificar ${ }^{18}$ un área próxima al centro de la ciudad, da cuenta de la pluralidad de sentidos que se proyectan en el espacio y de las disputas por la apropiación de un determinado sector urbano. Es, asimismo, uno de los ejemplos más claros de las tensiones de crecimiento que pueden reconocerse en el devenir de la ciudad 
de San Carlos de Bariloche. El derecho al hábitat y la vivienda digna para los sectores populares se contraponía -y era relegado-al interés del municipio de generar una importante inversión económica, que modernizara el sistema de comercialización local y promoviera el crecimiento.

Si bien existía todavía un remanente de tierras que podrían ser utilizadas para el proyecto habitacional, este proyecto se va desdibujando en el marco de autoritarismo del gobierno de facto que se mantiene en el poder hasta 1973. En esta época se puede constatar la conformación de un clima de creciente xenofobia y clasismo, impulsado denodadamente por el gobierno dictatorial (Núñez 2003). Los vecinos que ocupaban el espacio desde hacía casi 30 años, se descubren como "intrusos", al tiempo que el área que habitan empieza a perder progresivamente su carácter periférico por la expansión del área central.

Sin embargo el interés económico se cubre de supuestos ideológicos, donde la idea de "intruso" se arraiga en consideraciones nacionalistas y xenófobas. No es menor que desde mediados de los 60 se comenzara la edición de textos emblemáticos para comprender el territorio patagónico como parte de la Nación (Ygobone 1964; Bustillo 1968; Biedma 1967). Núñez (2003) reconoce que, a partir del golpe de Estado de 1966, la retórica "antichilena" aparece en forma recurrente en la localidad.

El actual barrio 10 de Diciembre, que en ese entonces también se conocía como "Barrio Lahusen" -por el nombre del supermercado- es cubierto por este estigma, sobre todo en la década de 1970. A partir de 1973, año en que se produce el golpe de Estado en Chile que derroca al presidente Salvador Allende, se produce la llegada de un alto número de inmigrantes chilenos a Bariloche (Matossian 2009). Algunos de estos migrantes se ubican en el barrio, entre otros espacios de la ciudad. Recientes estudios muestran cómo los sectores que nuclearon población chilena, diseñaron estrategias sociales de reconocimiento propias, con mayor o menor éxito, para otorgar legitimidad a la presencia de los nuevos habitantes ${ }^{19}$. Pero en el caso del barrio que nos ocupa, los nuevos inmigrantes fueron el argumento para que todo el poblamiento se ubicara en el sitio del usurpador y el delincuente.

Es destacable que ante una coyuntura de vigorosas presiones en pos del desalojo, los vecinos apelaran a la mediación del comandante del Regimiento 34 de Gendarmería Nacional, ubicado en las inmediaciones del barrio. Las memorias recuerdan que el comandante fue a la Intendencia a interceder en favor de ellos, porque eran "gente trabajadora" 20 . Esta mediación, más la incipiente organización vecinal, ayudaron a debilitar la concepción más dura que respecto de los pobladores se intentaba instalar desde cierto sentido común xenófobo y clasista. A partir de estos testimonios es posible reflexionar sobre la profunda imbricación entre la categoría nativa ${ }^{21} \mathrm{de}$ "gente trabajadora" y el derecho al acceso y tenencia de la tierra en Bariloche. Solo aquellos que fueran identificados como pertenecientes a dicha categoría por alguna institución mediadora, como la Iglesia (Núñez y Barelli 2013), o en este caso Gendarmería, tenían un legítimo acceso a la tierra, con mayores o menores facilidades. El resto, los "intrusos", se constituyen en los agentes que obstaculizaban ese desarrollo armonioso.

El barrio quedó en una situación intermedia, no se desalojó pero tampoco se ordenó la tenencia definitiva de la tierra, ya sea en forma de propiedad, alquiler, comodato o cualquier otra forma de tenencia. Por el contrario, la entrega de tierras no se detuvo nunca. Una serie de iniciativas institucionales comenzaron a localizase en el lugar, como el Colegio María Auxiliadora de la orden Salesiana, reconocido en catastro a partir de 1975.

Las memorias barriales reconocen, a partir del golpe de 1976, una creciente presión en pos del desalojo de la población del barrio, con un punto crítico en 1982, cuando enfrentaron el intento material de erradicación forzosa (Núñez y Guevara, 2014). Parecía que con el devenir del gobierno dictatorial se recrudecía la presión en pos de la relocalización compulsiva de aquellas situaciones de tenencia precaria. "Vivíamos el día, sabíamos que era el barrio de paso, la tierra prestada", recuerda Norma ${ }^{22}$, quien llegara a la localidad a mediados de los años setenta.

No obstante, tampoco emergía una formulación clara de proyecto alternativo para la zona, sino un conjunto de iniciativas dispersas. Después del breve interregno democrático entre 1973-1976, la última dictadura retomó con fuerza el reconocimiento diferenciado de la población a partir de consideraciones clasistas y xenófobas. Por ejemplo, los chilenos aparecían como los grandes responsables de las limitaciones del servicio público de salud del Hospital Zonal de Bariloche (Núñez, 2003), una crítica que los vecinos recuerdan como parte de los argumentos para erradicarlos ${ }^{23}$. La voluntad 
de desalojo se vinculaba más entonces a los prejuicios que a una planificación alternativa para la zona. Las presiones evidenciaron que el gobierno municipal se encontraba, en esos años de dictadura, claramente alineado con los intereses económicos más importantes de la ciudad, entre ellos el sector inmobiliario y el turismo. La estética del paisaje y el destino turístico se tomaban como fundamento para el reordenamiento urbanístico y poblacional. Así, a partir de 1981, y en consonancia con lo que se vivenció en muchas otras ciudades del país, se impulsaron varias iniciativas en pos de erradicar "villas de emergencias"24. El barrio 10 de Diciembre, a los ojos del gobierno municipal, se incluía en este universo. Algunos barrios fueron tomados como ejemplos de mejora, como el caso del Mallín, donde se otorgan créditos y tenencias oficiales (Núñez y Barelli 2013), pero otros son atacados, desarrollando estrategias para empeorar la calidad de vida en los mismos, como el caso de Pilar 1 (Núñez 2008).

En el barrio que nos ocupa se gestó una organización barrial "desde abajo" (Di Virgilio, 2011), que se ocupó especialmente de mostrar al resto de los vecinos, y sobre todo a los gobernantes, que estaban dispuestos a resistir el desalojo, porque eran sectores de trabajadores que no se negaban en principio a trasladarse, sino a ser echados sin una alternativa habitacional que cumpliera con ciertos estándares mínimos. La alternativa que se va formando, en esa suerte de reconocimiento intermedio, fue un plan de viviendas en el sector sur de la ciudad, que se diseña durante la dictadura, pero que se comienza a implementar ya en democracia, a partir de 1983.

Es tal la confianza que los vecinos depositaron en el proceso democrático que se inaugura con las elecciones de $1983^{25}$, que el 10 de diciembre de ese año, en ocasión de la designación presidencial de Raúl Alfonsín, bautizan al espacio que ocupan con esta fecha, que expresa sus expectativas en el período que se iniciaba. Pero la democracia estaba lejos de poder superar las contradicciones inherentes al modelo de desarrollo local que se consolidaba en Bariloche. La gestión municipal de 1983 heredó la decisión de asignar a ese territorio un nuevo rol en la dinámica de la ciudad.

Entre las soluciones ideadas estuvo el armar un nuevo Centro Administrativo en las tierras del barrio. Este plan se vinculaba con la disputa que enfrentaba la gestión municipal con la Administración de Parques Nacionales por el uso del Centro Cívico ${ }^{26}$.
El plan contemplaba que se destinara una parte a la construcción de viviendas sociales en cabeza del Instituto de Planeamiento y Promoción de la Vivienda (IPPV), pero como esta solo era una parte minoritaria, igualmente se planteaba la relocalización de casi la totalidad de la población asentada en el lugar. Dentro del barrio, los boletines comunitarios que se publican en la época son una muestra del trabajo conjunto que se llevaba adelante y del compromiso de participación de los vecinos, que siguen permanentemente las obras de la Quinta 58, espacio acordado para el traslado de la mayor parte de la población (ver Figura 3 Boletín 5, 1987, pp. 1-2).

De acuerdo con las fuentes legales, el municipio de San Carlos de Bariloche adquiere las tierras en julio de 1981 por medio de la Escritura № 56 al Banco Hipotecario Nacional. En 1983, la Ordenanza 25-I-83 dona a título gratuito y otorga a título de propiedad al IPPV los lotes designados catastralmente como 19-2-E-187-10, 11, 12, 13, 17, $18,19,20$ y 21 , que pertenecen al espacio original del barrio para la construcción de setenta viviendas. No obstante, el IPPV construyó solo treinta unidades funcionales. El resto de las tierras, en lugar de disponer su urbanización o la construcción de viviendas sociales nuevas, como era el proyecto

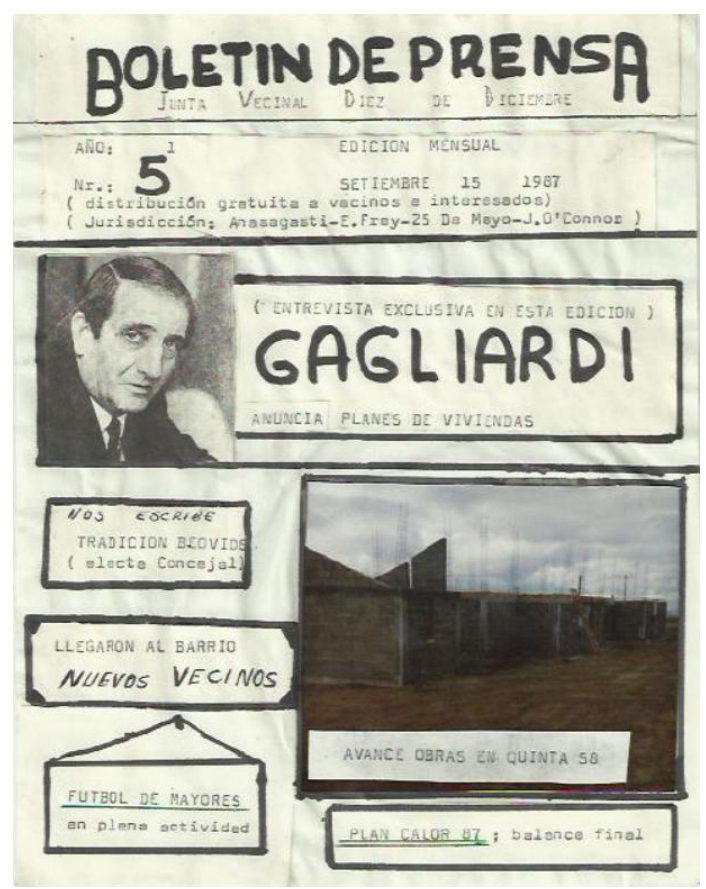

Figura 3: Boletín de Prensa No 5 Junta Vecinal Diez de Diciembre. Fuente: Comisión de Tierras Barrio Diez de Diciembre. 
original, se buscó destinarlas para la construcción del mencionado Centro Administrativo, mediante la Ordenanza 167-I-83, para ello declara a las parcelas restantes de dominio público.

El cambio de destino para las tierras en cuestión contaba con numerosos antecedentes previos. En 1964, el estudio de Hardoy había planteado la posibilidad de que las parcelas del BHN fueran canjeadas para llevar los proyectos de vivienda social más hacia el este, como forma de promocionar un área de viviendas económicas, y que esas parcelas fueran destinadas a otros usos, según la característica de centro secundario del área.

Asimismo, el estudio de Suárez, de 1977, planteaba que, debido a la elevada centralidad del Centro Cívico y la escasa desconcentración de las actividades, era necesario mejorar las condiciones de acceso e infraestructura sobre la "plataforma" en la meseta ${ }^{27}$, favoreciendo a su vez la incorporación de la zona este de la ciudad. Esto ayudaría, según se afirmaba, a consolidar un centro secundario para la población de residencia permanente.

La localización del Centro Administrativo en las tierras donde se ubica el barrio 10 de Diciembre es consonante con este esquema prospectivo del estudio de Suárez. También se preveía la construcción de una Ciudad Judicial en la zona, para alojar a los diferentes juzgados y cámaras dispersos en la ciudad en edificios poco aptos para esa finalidad. Las concepciones sobre qué lugar debían ocupar los sectores populares en la estructura urbana se expresaban de esta forma con claridad en los instrumentos urbanos que, como toda política pública, expresan el estado de correlación de fuerzas entre los diferentes sectores sociales en pugna (Oszlak, 1991). No obstante, prácticamente nada de esta planificación termina materializándose en el espacio barrial, a excepción de treinta viviendas del IPPV, que todavía hoy permanecen.

Recapitulando sobre los documentos municipales podemos encontrar claves para entender los vaivenes en torno al modo de definir la ocupación del predio. La Ordenanza 167-I-83 declara la utilidad pública del predio en disputa, en el contexto de conflicto con la APN sobre el uso del Centro Cívico.

Desde el municipio, ya en 1984, por la Ordenanza 56-C-1984, se ratifica el Acta Intención suscrita con la Administración de Parques Nacionales por el traspaso del Centro Cívico hacia el municipio, abriendo una vía de solución al conflicto por las dependencias del gobierno local.
En este escenario de recuperación de la democracia se afianza el trabajo con los vecinos para lograr un traslado de común acuerdo. La Ordenanza 159-C-86 afectó para el realojamiento habitacional de familias del barrio una parcela cuya superficie abarcaba más de 4 hectáreas, donde se construyó el 28 de abril (ver Figura 1). No obstante, una parte de la población estaba decidida a resistir. En 1987 se constituyó formalmente la Junta $\mathrm{Vecinal}^{28}$ Barrio 10 de Diciembre, cuando la Ordenanza 57-C-1987 le da Personería Jurídica Municipal, lo que implicó un aval político importante para la consolidación de la organización barrial y la permanencia en el lugar.

Se pueden identificar al menos dos factores que explican el "fracaso" del municipio para impulsar la transformación del área. En primer lugar, el complejo acuerdo entre vecinos y municipio y la distancia entre las expectativas de la organización barrial y los funcionarios municipales. En los sucesivos boletines se observa claramente que la confianza se va debilitando con el correr del tiempo, generando que varias familias abandonen la idea del traslado y empiecen a manifestar voluntad de quedarse en el lugar (ver Figura 4 Boletín 6, 1987, p. 1), los que terminarían expresándose en el reconocimiento de

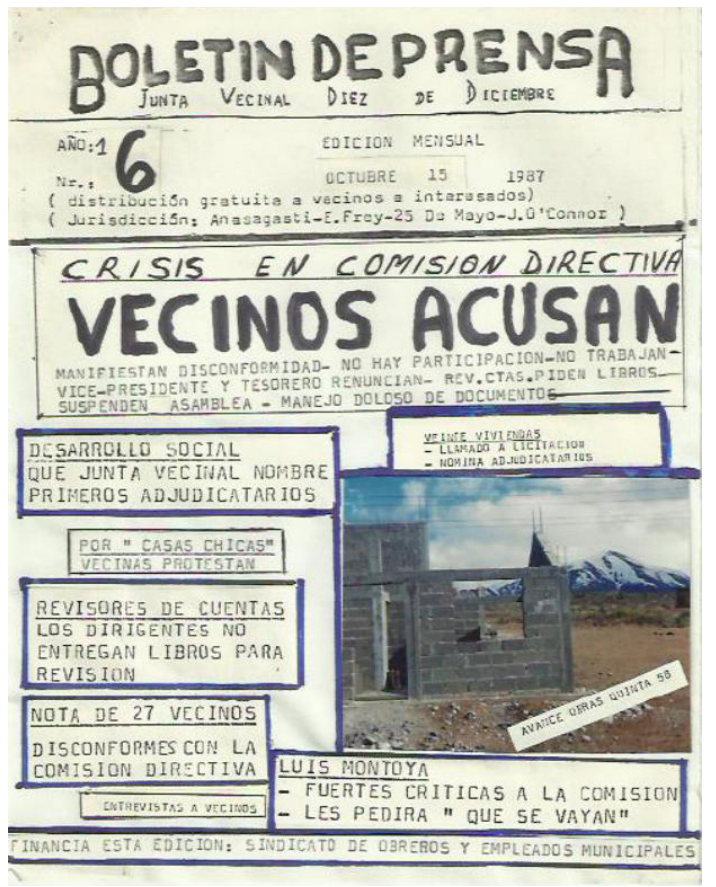

Figura 4: Boletín de Prensa No 6 Junta Vecinal Diez de Diciembre. Fuente: Comisión de Tierras Barrio Diez de Diciembre. 
la Junta. Al mismo tiempo, los dirigentes barriales se ven obligados a clarificar los rumores esparcidos por funcionarios municipales y comunicar lo que efectivamente se estaba sancionando (ver Figura 5 Boletín 9, 1990, p. 1-2). En segundo lugar, la dificultad de parte del municipio para dar forma acabada a un plan alternativo para el territorio en disputa, que sirviera para legitimar y fortalecer la idea de desalojo. De hecho, que de una parte se buscara propiciar el traslado, mientras que otras áreas del municipio daban reconocimiento legal a la forma de organización comunitaria habla de las diferentes visiones e intereses contrapuestos que había en el seno del gobierno local sobre el destino del barrio.

La relocalización se hizo efectiva en forma gradual y parcial, en el marco del Conjunto Habitacional 28 de Abril, pero no se trasladó a la totalidad de la población del barrio porque algunos vecinos se negaron. La posición oficial era tan ambigua que, de hecho, algunos vecinos tardaron más de un año en mudarse al nuevo conjunto pese a tener la nueva vivienda asignada ${ }^{29}$. Paralelamente, el conflicto entre la APN y el municipio se resolvía, dejando las oficinas de gobierno en el espacio original, lo que descomprimió la necesidad del gobierno local de contar con oficinas alternativas y desactivó en consecuencia el proyecto del Centro Administrativo. La Ordenanza 84-C-1987 ratifica el convenio suscrito

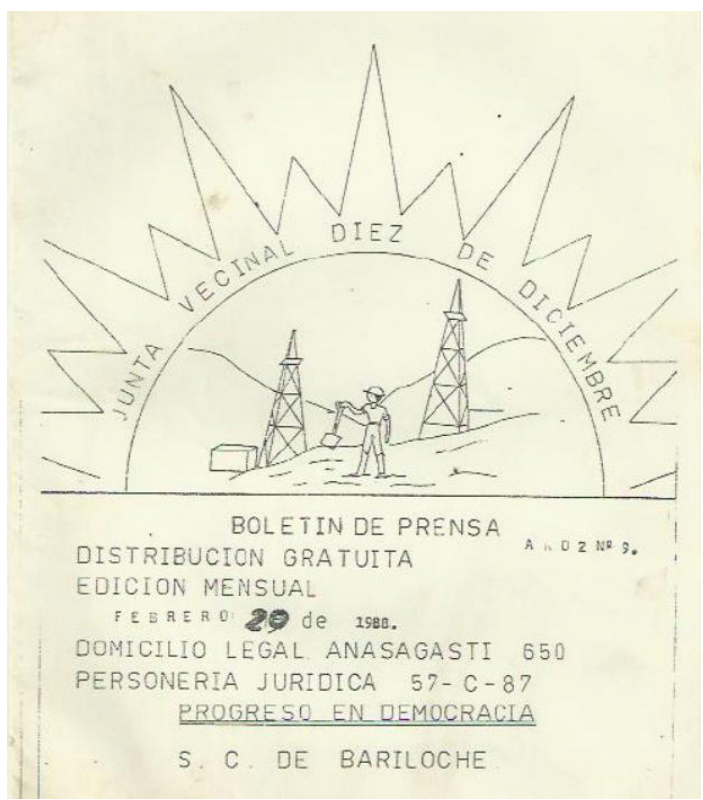

Figura 5: Boletín de Prensa No 9 Junta Vecinal Diez de Diciembre. Fuente: Comisión de Tierras Barrio Diez de Diciembre. entre la Administración de Parques Nacionales y la Municipalidad por el traspaso del dominio del Centro Cívico.

No obstante, un año antes encontramos todavía la intención de materializar la también planificada Ciudad Judicial: la Ordenanza 118-C-1986 faculta al Presidente del Concejo a suscribir un Convenio con el Poder Judicial de la Provincia de Río Negro, para establecer las pautas de cesión de tierras por parte de la Municipalidad para la construcción de un edificio que nuclée el funcionamiento del Poder Judicial en el espacio que no terminaba de ser desocupado.

El espacio, que nunca se terminaba de despoblar completamente, se llenaba de proyectos alternativos en disputa, que expresaban intereses económicos, políticos y corporativos diversos (Guevara, 2013). Como la Ordenanza 561-CM-1991, que declaró espacio verde con destino a plaza pública algunas manzanas del barrio, o la Ordenanza 893-CM-98 y su ampliación por Ordenanza 1091-CM-00, que ceden en forma gratuita lotes para la construcción de un colegio (el Centro de Educación Media 36). Lo que todos estos proyectos tenían en común era la decisión de excluir a los sectores populares de un área que empezaba a ser cada vez más céntrica y relocalizarlos hacia el sur, una de las áreas definidas para la localización de esos sectores.

En general, los avances que debían realizarse en el nuevo conjunto 28 de Abril fueron lentos y problemáticos. Esto se refleja en las denuncias publicadas por el boletín comunitario, por ejemplo en relación con la molestia por el tipo de viviendas, que eran muy chicas (ver Figura 4 Boletín 6, 1987, p. 1-3).

La relocalización parcial determinó que las tierras nunca terminaran de ser liberadas, imposibilitando que se afirmara cualquier uso alternativo. Por el contrario, la población remanente fue el anclaje de un nuevo proceso poblacional, que ya comenzaba a observarse aun cuando no se habían terminado los traslados. Durante la década de 1990 se genera una intensa corriente migratoria proveniente sobre todo de las localidades rurales cercanas a Bariloche ${ }^{30}$. Este proceso de repoblamiento empezó a saldar la disputa entre los proyectos para las tierras donde se asentaba el barrio, por la imposibilidad de su traslado definitivo.

Este repoblamiento puso en evidencia la falta de decisión por parte del municipio en torno a la concreción de los proyectos alternativos para 
el área, que fueron progresivamente dejados de lado $^{31}$. No obstante, la definición de urbanizar y consolidar a la población allí asentada tampoco se tomaba, generando con esta omisión condiciones habitacionales muy precarias en el barrio.

Se llega así al crítico escenario del $2001^{32}$, que marca entre otros factores la emergencia y protagonismo de los espacios de organización de base en todo el país. En el barrio 10 de Diciembre este proceso se expresa en la conformación de la Comisión de Tierras (CT) en el 2003, como una organización de base que toma como único objetivo el trabajar en pos de la regularización dominial de los lotes. Se afirma como un espacio alternativo al de la Junta Vecinal, debido a que se plantea la necesidad de una mayor autonomía para negociar frente al municipio, al tiempo que busca alejarse de las obligaciones vinculadas al área de Acción Social municipal, como el reparto de leña-que en muchos casos introducían quiebres en la organización a causa de las respuestas incompletas del gobierno municipal ${ }^{33}$.

La CT, además, se caracterizó por no tener roles fijos y poseer un funcionamiento asambleario. Los vecinos que la formaban recuerdan en sus testimonios las dificultades para lograr instituirse como representantes del resto de los pobladores, así como los permanentes desafíos para sostener la acción vecinal. Una de las estrategias iniciales fue la realización de un censo poblacional que pusiera en evidencia la situación que se buscaba resolver. Esto se hizo con el acompañamiento de los referentes territoriales de la oficina de Acción Social del municipio. En octubre del 2003 se relevaron ciento diecinueve familias, algunas de ellas se mudaron en los años siguientes, pero que permitió reconocer una problemática habitacional que afectaba a cuatrocientas cuarenta personas.

El censo puso de relieve a su vez que el problema habitacional no solo se vinculaba a la falta de reconocimiento de la tenencia, sino también a la precariedad de las construcciones. Las viviendas se caracterizaban por su escasa superficie (superficie promedio de $20 \mathrm{~m}^{2}$ ), falta de espacios diferenciados, pérdida excesiva de calor, elevada posibilidad de incendios (el $80 \%$ era completamente de madera y la única forma de calefacción era la leña), ambientes oscuros y escasa ventilación. En general, tenían pisos de tierra o cemento, chapas de cartón en el techo y letrinas en el exterior. El plan para llevar adelante el tendido de la red cloacal es una de las iniciativas de mayor impacto que impulsa la CT, que se materializa finalmente en 2005. El recuerdo y el miedo a los incendios acompañaba todas las reflexiones de los miembros de la actual CT.

A mediados de la década de 2000, la gestión vecinal logra la aprobación de dos ordenanzas centrales para la organización del territorio. La Ordenanza 1586-CM-2006, que toma como antecedente el censo de 2003, estableció la regularización dominial de los ocupantes del barrio 10 de Diciembre. En ese momento, de 96 lotes adquiridos por compra con destino al Centro Administrativo, restaban 47 lotes, de extensiones variables entre 100 y $500 \mathrm{~m}^{2}$, repartidos en dos manzanas y media. Se encontraban ocupados por alrededor de 119 familias. En agosto de 2006 la Subsecretaría de Planeamiento concluyó con la elaboración de un proyecto de urbanización de las parcelas resultantes de la unificación de los inmuebles indicados en el artículo segundo de la Ordenanza 1586-CM-06 y de un prototipo de vivienda social en conformidad con la comisión de vecinos.

Para la materialización del proyecto se afectó la parcela identificada catastralmente como 19-2-E187-26 que, una vez subdividida, permitiría obtener 123 lotes cubriendo casi la totalidad de las familias que habitan el barrio. La Ordenanza 1785-CM-2007 aprobó la afectación de dicha parcela y aprobó el proyecto de urbanización del barrio.

En marzo de 2007 se conformó una "Comisión Mixta" entre representantes de las áreas municipales mencionadas y la CT, estableciendo una mesa de trabajo que ha permitido afianzar un complejo proceso de urbanización, aún en desarrollo ${ }^{34}$.

El modo de gestión de la organización barrial y su delicada vinculación con los actores institucionales responsables de llevar adelante el plan de obras determinó la lógica de la lucha en una estrategia de bajo perfil, limitada salida a la prensa y los medios, diálogo interinstitucional cuidado, exacerbando el carácter particular de la iniciativa -es decir, de difícil réplica en otras áreas de la ciudad-. En este sentido, se plantea una suerte de híbrido entre los tipos de organización social de base planteado por Herzer (2004): prestación de servicio y autoorganización, porque la CT conjugaba la horizontalidad y la rotación de roles del segundo tipo con una manejo muy particular de los tiempos para "activar" a la población del barrio, más compatible con el verticalismo del primer tipo. Esto se ve muy claro en los relatos de cómo los miembros de la CT elegían los momentos adecuados para hacer asambleas y 
mostrar actividad, y aquellos donde lo que se necesitaba era trabajar "hacia adentro"35.

Estas particularidades de la organización barrial y sus indudables logros en términos de conquista de derechos nos llevan a preguntarnos por la dinámica política y social de una ciudad que, lejos de dar lugar a movimientos comunitarios extendidos y con articulaciones horizontales, parece reunir dinámicas barriales con diferencias mayores que las similitudes, dando lugar a procesos fragmentados.

De allí que, incluso observando un proceso exitoso de mejora habitacional resultante de la autogestión comunitaria, nos interrogamos acerca de la efectiva integración social, económica y urbana del barrio en cuestión.

\section{El Barrio 10 de Diciembre y su integración social y urbana}

El barrio 10 de Diciembre permite (re)pensar las relaciones entre el desarrollo urbano y económico de una ciudad, ya que puede ser interpretado como un ejercicio de resistencia al modelo hegemónico de ciudad y a las políticas urbanas que se ponen al servicio de dicho modelo. Podemos reconocer dos etapas de esta resistencia: primero, la lucha por el derecho a ser reconocidos como vecinos ejercitada por una organización que se forja para enfrentar a la dictadura militar y se termina desdibujando por las erráticas políticas de la naciente democracia. La segunda, la de la CT posterior a 2003, ya claramente contraponiéndose al embate de las concepciones más neoliberales del urbanismo -que restringían el acceso a la tierra y, por qué no, a la centralidad urbana (derecho a la ciudad) - y trabajando un proyecto de regulación dominial definitivo. Podemos inscribir este caso en un amplio espectro de experiencias que, desde diferentes organizaciones de base, han buscado edificar alternativas en un contexto difícil, dando lugar a un conjunto de iniciativas que no se terminan de articular (Iuorno y Pasquali 2012).

El barrio 10 de Diciembre, como caso emblemático de un barrio popular de San Carlos de Bariloche, no está incorporado en términos generales en la propuesta hegemónica de economía turística. Pero esta falta de integración al proyecto centrado en el turismo no se agota, ni mucho menos, en lo laboral. El tipo de urbanización de Bariloche hizo que el acceso de los sectores populares al suelo urbano sea por lo general en condiciones de informalidad y precariedad, donde el habitante es responsabilizado por la vulnerabilidad de su situación y la precariedad de las construcciones presentadas como argumento de la ilegitimidad del asentamiento.

El caso del barrio 10 de Diciembre permite entrecruzar en el análisis las dinámicas territoriales con las dinámicas de integración social y económica. En este caso se conjugó la permisibilidad o falta de regulación por parte del municipio para impedir dicho asentamiento con una falta total de políticas de suelo y vivienda para dar respuesta a la demanda de la población que llegó a asentarse en la ciudad y que en muchos casos fue invitada a ubicarse en ese espacio, para después ser tildada de intrusa.

Junto a las marcas materiales, en los relatos descubrimos en las construcciones simbólicas formas de fragmentación que impactan en el tejido social e incluso hacen mella al interior del heterogéneo espectro de los sectores populares. Creemos que esta fragmentación se relaciona estrechamente con -y permite interpretar en su contexto- la estrategia desarrollada por la CT de mantener un "perfil bajo" para impulsar sus reivindicaciones. Podría plantearse a modo de hipótesis interpretativa que el barrio 10 de Diciembre, en alguna medida, "ganó" su lugar en la ciudad (especialmente desde la recuperación de la democracia) mediante "grietas" del sistema, aprovechando una ventana de oportunidad (Tarrow, 1998) que determinó una coyuntura de apertura del gobierno municipal (Guevara, 2014), y no tanto por medio de una resistencia combativa, que sí estuvo presente durante la resistencia al desalojo en 1981-2.

Esto no implica restarle méritos ni heroicidad a la lucha, sino que apunta a reflexionar sobre las condiciones de posibilidad de la acción social reivindicativa en esta ciudad. El barrio pudo terminar de afianzarse en el lugar porque las deficiencias en términos de planeamiento de la Municipalidad no supieron generar una propuesta alternativa acabada para esas tierras. El barrio 10 de Diciembre "ganó" más por persistente y tenaz que por un conflicto explícito. Es más, parte de su estrategia ha sido evitar el conflicto abierto, llevando propuestas de soluciones en el proceso mismo de presentación de las demandas ${ }^{36}$. Esta estrategia demanda una buena organización barrial, espacios estos que muchas veces se encuentran obstaculizados por las dificultades cotidianas que impactan en las posibilidades de participación de los vecinos.

Este reconocimiento tiene una arista que es necesario explicitar: entendemos que la estrategia desplegada por la CT se inscribe en una configuración 
ciudadana que ha fomentado las diferencias antes que los encuentros entre los habitantes más desfavorecidos de la ciudad. La fragmentación imperante dificulta la conformación de un movimiento social más amplio por el hábitat y el derecho a la ciudad que sea capaz de modificar la orientación de las políticas urbanas locales (Harvey, 2013). Este movimiento implicaría, además, revisar el proyecto económico hegemónico para la ciudad, desatando toda una suerte de oposiciones y disputas con diferentes actores e intereses. Todo esto permite cuestionar seriamente en qué medida la integración urbana y social del barrio está garantizada, aunque se reconozcan procesos barriales exitosos de reconocimiento de derechos, como el caso de su urbanización.

En la medida que la propuesta hegemónica de la economía turística no abra lugar para otras iniciativas y propuestas de desarrollo y en la medida que la dinámica inmobiliaria especulativa no permita democratizar el acceso a la tierra se puede afirmar que estos procesos de integración encontrarán numerosos obstáculos y están bajo la amenaza de quedar truncos. Asimismo, es necesario destacar que cuando no se resuelve eficazmente la integración, se produce de manera casi inmediata la emergencia de nuevas problemáticas, como por ejemplo el hacinamiento por la cohabitación de diferentes generaciones -los hijos crecen, se juntan, tienen hijos, y no tienen otra opción muchas veces que vivir en la misma casa de los padres-.

El diálogo del proceso barrial con la dinámica urbana ampliada abre más interrogantes y certezas, en una ciudad que no termina de perfilar una política clara de integración social, económica y urbana para una gran parte de su población.

\section{Conclusiones}

Este trabajo llevó adelante una reflexión en torno a la relación entre los modelos de desarrollo económico y urbano de las ciudades contemporáneas, partiendo de la constatación de que dicha relación muchas veces es perdida de vista en los abordajes empíricos, priorizando un componente sobre el otro.

Para ello se llevó adelante un estudio de caso sobre el barrio 10 de Diciembre, a partir de un análisis de fuentes documentales y entrevistas en profundidad con referentes del barrio que recuperan la historia oral de procesos que no han sido debidamente registrados.
El proceso de conformación histórica del barrio estuvo vinculado a la incapacidad original para materializar un proyecto de vivienda de interés social para trabajadores en una localización originalmente periférica. La ocupación informal de las tierras fue promovida y avalada desde el municipio, pero cuando la expansión de la ciudad determinó que su localización coincidía con la de una centralidad secundaria reconocida en los diferentes instrumentos de política urbana se desató un conflicto entre diferentes proyectos alternativos para las tierras.

Esta disputa nos permitió poner en diálogo los procesos de uso y apropiación del espacio urbano en un lugar determinado de la ciudad, mediados por las instancias de implementación de políticas urbanas y de ordenamiento y planeamiento del territorio, con el modelo de desarrollo económico hegemónico, que se asienta en la preeminencia de los intereses del sector turístico. Este modelo de ciudad promueve cierta imagen que determina la localización de los sectores populares en la periferia hacia el sur, por fuera de la ciudad turística.

La localización del barrio 10 de Diciembre desafió este patrón de localización generando un proceso de resistencia que logró mantener con éxito a lo largo del tiempo. En gran medida, la incapacidad de la Municipalidad para concretar alguno de los proyectos alternativos fue el resquicio por donde la resistencia barrial logró colar su reclamo, que al final conquistó la urbanización definitiva, hoy en proceso avanzado de realización.

La historia reciente del barrio 10 de Diciembre nos permite reflexionar sobre las articulaciones en el territorio concreto entre los modelos de desarrollo económico y desarrollo urbano impulsados por parte de los gobiernos locales, y en qué medida estos modelos y su articulación estructuran las posibilidades reales de integración social, económica y urbana de los sectores populares a la ciudad.

\section{Agradecimientos}

Los autores agradecen a la Universidad Nacional de Río Negro (UNRN) y al Consejo Nacional de Investigaciones Científicas y Técnicas de la República Argentina (CONICET). Asimismo, agradecemos a los entrevistados y fuentes sobre las que se basa este artículo por su aporte a la construcción de la historia oral del barrio. 


\section{Referencias Citadas}

Abalerón, A

1995 Difusión espacial de la pobreza y destrucción del patrimonio natural: las dos caras de una misma moneda. Revista EURE, XXI, 64, 61-74, diciembre 1995, Santiago de Chile.

Abalerón, A.

2005 Encuesta de la situación laboral, vivienda, educación e ingresos. Programa Calidad de Vida-Fundación Bariloche, San Carlos de Bariloche, Argentina.

Ainstein, L., S. Kralich, J. Villadeamigo y T. Guevara 2012 Una modelización comparada relativa a Grandes Aglomerados Compactos y Grandes Aglomeraciones Difusas. En Estructuración Urbana, institucionalidad y sustentabilidad de ciudades metropolitanas y regiones difusas. Miradas comparadas de Buenos Aires / Londres /Los Ángeles / París / Tokio / Toronto. EUDEBA, Buenos Aires.

Bessera, E.

2011 Exequiel Bustillo y la gestión de los parques nacionales. Araucanía - Norpatagonia. Cultura y Espacio, pp. 115-124. IIDyPCa - CONICET-UNRN.

Biedma, J.M.

1967 Toponimia del Lago Nahuel Huapi. Buenos Aires: DPN.

Bustillo, E.

1971 El despertar de Bariloche. Una estrategia patagónica. Casa Pardo, Buenos Aires.

Di Virgilio, María Mercedes

2011 Producción de la pobreza y políticas públicas: encuentros y desencuentros en urbanizaciones populares del Área Metropolitana de Buenos Aires. En Arzate Salgado, Jorge, A. Gutiérrrez, J. Huamán (Coord.). Reproducción de la Pobreza en América Latina y el Caribe. Relaciones sociales, poder y estructuras económicas. CLACSO-CROP, Buenos Aires.

Duhau, Emilio y Ángela Giglia

2004 Conflictos por el espacio y orden urbano. Estudios Demográficos y Urbanos, 56, mayo-agosto, 257-288. Colegio de México, México DF.

Fanjul, J.D.

1964 Breves Lineamientos para una política turística (Manuscrito). Municipalidad de San Carlos de Bariloche.

Glaser, B. y A. Strauss

1967 The discovery of grounded theory: strategies for qualitative research. Aldine Publishing Company, New York.

Grillo, Oscar Jorge

1988 Articulación entre sectores urbanos populares y el Estado local (el caso del barrio de La Boca). Centro Editor de América Latina, Buenos Aires.

Guevara, Tomás

2010 Políticas habitacionales y procesos de producción del hábitat en la Ciudad de Buenos Aires. El caso de La Boca. Tesis de Maestría en Políticas Sociales. Universidad de Buenos Aires.

Guevara, Tomás

2013 ¿La ciudad para quién? Transformaciones territoriales, políticas urbanas y procesos de producción del hábitat en la Ciudad de Buenos Aires (1996-2011). Tesis para optar por el título de Doctor en Ciencias Sociales. Universidad de Buenos Aires.
Harvey, David

2013 Rebel Cities. From the Right to the City to the Urban Revolution. Verso, Londres.

Herzer, Hilda

2008 Con el corazón mirando al sur. Transformaciones en el sur de la ciudad de Buenos Aires. Espacio Editorial, Buenos Aires.

Iourno, G. y L. Pasquali (compil.)

2012 Resistencias al proceso de embate neoliberal en Argentina. Aproximaciones desde la Historia Oral. Prohistoria, Rosario.

Jaramillo, $S$.

2009 Hacia una teoría de la renta del suelo urbano. Universidad de Los Andes, Bogotá.

Lolich. L.

2010 Los planes urbanos y su relación con el paisaje cultural en zonas de frontera. Caso Bariloche, Patagonia argentina. 1934 - 1979. En Miradas Transcordilleranas, pp. 106-126. IIDyPCA-UNRN, Bariloche.

Matossian, B.

2009 Expansión urbana y migración chilena: estrategias comunitarias para la conformación de barrios populares en San Carlos de Bariloche. XIX Encuentro Nacional de Profesores en Geografía, San Carlos de Bariloche, Argentina.

Municipalidad de San Carlos de Bariloche

1977 Plan de Ordenamiento Territorial. Análisis y diagnóstico. San Carlos de Bariloche.

Municipalidad de San Carlos de Bariloche

1964 Plan Físico para San Carlos de Bariloche (Manuscrito). San Carlos de Bariloche.

Núñez, Paula

2003 Un municipio alejado, una actividad tangencial y los efectos de un profundo cambio institucional. San Carlos de Bariloche, 1950-1970. Tesis de licenciatura en Historia. Universidad Nacional del Comahue.

Núñez, P.

2004 Un municipio alejado, una actividad tangencial y los efectos de un profundo cambio institucional. San Carlos de Bariloche 1958-1970. Cuadernos del Sur. Revista de Historia, 34, 169-188.

Nuñez, P.

2008 Historia del presente en Pilar 1. En Robles - Pilar 1. Identidad y Lucha por la Tierra. Núcleo Patagónico, Bariloche.

Núñez, P. y I. Barelli

2013 Marcas urbanas y sentidos sociales en disputa. Bariloche, (1966-1983). HiSTOReLo. Revista de Historia Regional y Local, (5), 10, 164-196.

Núñez, P. y T. Guevara

2014 La frontera, la nación y el barrio: un diálogo interescalar entre lo argentino y lo chileno desde San Carlos de Bariloche. Revista de Estudios Sociales (en evaluación). Mimeo.

Oglietti, G. y E. Colino

2010 La cepa turística de la enfermedad holandesa: Diagnóstico y tratamiento para San Carlos de Bariloche. Ponencia presentada en 2 do. Congreso anual de la Asociación de Economía para el Desarrollo de la Argentina "Lineamiento para un cambio estructural de la economía argentina. Desafíos del bicentenario". 
Oszlak, O.

1991 Merecer la ciudad: los pobres y el derecho al espacio urbano. Humanitas, Buenos Aires.

Piglia, M.

2010 De la Dirección de Parques Nacionales, a la Administración General de Parques Nacionales y Turismo: primeras experiencias de una política turística nacional centralizada (1934-1950). Ponencia presentada en V Jornadas de historia política "las provincias en perspectiva comparada" Universidad Nacional de Mar del Plata, 29 de septiembre al 1 de octubre de 2010.

Pírez, Pedro

2006 La privatización de la expansión metropolitana en Buenos Aires. Revista Economía, Sociedad y Territorio, (VI) 21, 31-54.

Plá, D.B.

2001 La historia oral, fuente importante para estudiar las migraciones. En Camarena y Villafuerte. Los andamios del historiador: construcción y tratamiento de fuentes. INAH-AGN. México.
Rodríguez, María Carla

2006 Tiempo de caracoles... Autogestión, políticas del hábitat y transformación social. Tesis para optar por el título de Doctora. Universidad de Buenos Aires.

Schwarzstein, D.

2001 Historia Oral, memorias e historias traumáticas. Historia Oral 4, 73-83.

Smith, Neil

2002 New globalism, new urbanism: gentrification as a global urban strategy. Antipode, 34, 427-450.

Tarrow, Sidney

1998 Power in movement. Social movements and contentious politics. Cambridge University Press, New York.

Vallmitjana, R.

1989 Bariloche, mi pueblo. Fundación Antorcha, Buenos Aires.

Ygobone, A.

1964. Renacimiento de la Patagonia. Contribuciones al estudio, investigación y solución de diversos problemas del sur argentino. Depalma, Buenos Aires.

\section{Notas}

1 Para un conflicto de similares características en el barrio de La Boca en CABA ver Grillo (1988).

2 Las entrevistas se realizaron en el marco del proyecto de Extensión "Identidad cultural e integración social en el barrio 10 de Diciembre de San Carlos de Bariloche" de la UNRN, los y las entrevistados forman o formaron parte de las comisiones barriales que buscaron organizar el espacio. Ellos son Luis Montoya, Ada Reiner y Norma Fuentes de la primera Junta Vecinal, Mario Hott, José Vargas, antiguos pobladores; Matías Calfuquir, Elena Sonda, Noemí (Mimi) Guajardo, Antonio Manuel, Gustavo Rodríguez y María Chandíaz, de la Actual Comisión de Tierras, quienes quisieron aportar sus memorias con nombre y apellido.

3 La extensión original era de 625 hectáreas y posteriormente a lotes agrícolas de entre 50 y 100 hectáreas.

4 Por ejemplo, la ladera norte del cerro Otto, la costa del lago Nahuel Huapi, la zona aledaña al lago Moreno, etc.

5 El caso más paradigmático es el barrio cerrado Arelauquen, con más de 780 hectáreas de extensión, a la vera de la Ruta 40 Sur, pero también se puede mencionar el barrio Pinar del Este, a la entrada de la ciudad.

6 Por ejemplo, el lago Gutiérrez y la villa Los Coihues.

7 Por ejemplo, el viejo camino a Colonia Suiza

8 Por ejemplo, el Punto Panorámico en Circuito Chico, copado por un parador y además atestado de puestos de vendedores ambulantes sin mayor regulación.

9 Creada por la Ley Nacional No 9.677 en 1915, para la construcción de viviendas de interés social.

10 Bariloche, como poblado, existe desde 1895. Fue reconocido como colonia agrícola en 1902 y, desde 1934, a partir de la creación de la Dirección de Parques Nacionales, se considera una urbanización dedicada exclusivamente a la actividad turística (Bessera, 2011).

11 En 1938, la Dirección de Parques Nacionales inició tratativas con la Comisión Nacional de Casas Baratas, ofreciendo cederle unos terrenos para que se construyeran casas económicas para los habitantes de Bariloche con viviendas precarias; a la vez, con una considerable preocupación por lo que las viviendas autoconstruidas le hacían al aspecto estético de la ciudad, la sección de arquitectura de la Dirección de Parques Nacionales entregó al municipio ocho diferentes planos-modelos de casas baratas para "facilitar a la población de escasos recursos" (Memoria DPN de 1938, 1939, p. 66). Citado en Piglia (2010: 22)

12 Si bien desde la década de 1930 el municipio existe como entidad político-administrativa, delegó prácticamente la totalidad de la función de planeamiento urbano en la APN.

13 Discurso con motivo de la creación de la Administración Nacional de la Vivienda Juan Domingo Perón [6 de junio de 1945].

14 José Vargas: "le llevé una botella de vino y me dio permiso para construir mi casa" (entrevista realizada por Paula Núñez, 25 de mayo de 2011).

15 Los fundamentos de la ordenanza señalan que el costo de la canasta familiar había generado la necesidad de un comercio de estas características. Se reconocía en el establecimiento de un supermercado la estrategia para lograr que los precios del consumo disminuyeran de manera efectiva. Así se resuelve dar lugar a la escrituración del Lote $\mathrm{N}^{\circ} 78$ a la Sociedad Anónima de Exportación e Importación Lahusen y Cía. Ltda. (Ordenanza 8-I-1970), adquirida en el marco de la Licitación No. 1/1970. Posteriormente, la Ordenanza 23 de 1972 reescribe el predio a favor de Tiendas y Almacenes Lahusen S.A.I.C.yA. (TALSA), evidenciando algún tipo de modificación en la personería jurídica.

16 Entrevista realizada por Paula Núñez a Luis Montoya, 25 de mayo de 2011.

17 Este establecimiento, ubicado en la esquina de Moreno y Villegas (ver Figura 1), fue un ámbito céntrico que nucleaba la comercialización de la producción local desde principios de siglo. En los años cuarenta, su remodelación fue parte del plan de obras de la Dirección de Parques Nacionales para la ciudad. Pero en los años 70 el edificio y la práctica comercial se desmantelaron, en línea con la decisión de 
establecer el supermercado (Núñez 2004) y consolidar una identidad ligada al turismo en detrimento de cualquier alternativa productiva.

18 Gentrificar refiere al proceso de renovación urbana de áreas degradadas de localización tradicional de sectores populares, su consecuente desplazamiento poblacional y la llegada de sectores medios acomodados. Para una revisión de la discusión sobre el origen y el contenido del concepto ver Herzer (2008).

19 Un ejemplo es el caso del barrio El Mallín donde, al contrario, se favoreció la radicación y reconocimiento de migrantes de origen chileno, mediante una activa movilización de la Iglesia católica.

20 Entrevista a Luis Montoya y Norma Fuentes, realizada por Paula Núñez el 25 de mayo de 2011.

21 Es un término que viene de la metodología cualitativa, especialmente la Teoría Fundada en los Datos (Glaser y Strauss, 1967).

22 Entrevista realizada por Paula Núñez el 25 de mayo de 2011 a Norma Fuentes, habitante del barrio.

23 Norma Fuentes, Ada Reiner, Mario Hott, Luis Montoya, Carmen Calfuquir. Entrevista realizada por Paula Núñez, 25 de mayo de 2011.

24 Tal vez el caso más destacable sea el de la ciudad de Buenos Aires que reconstruye Oszlak (1991) y que implicó el desalojo y relocalización de decenas de miles de hogares.

25 Este clima de optimismo y confianza era generalizado, de ahí que al período se lo conozca popularmente como la "primavera democrática".

26 Como indicamos, la Dirección de Parques Nacionales (después Administración) tiene una gran incidencia en el trazado urbano de San Carlos de Bariloche. La principal impronta de esta dependencia fueron las construcciones monumentales que hoy caracterizan a la ciudad, como el Centro Cívico, la Catedral, o el Mercado ya mencionado. Por esta tenencia en los 80, la Administración disputa al municipio el derecho al uso del Centro Cívico.

27 La morfología de la ciudad determina que las primeras cuadras desde el lago muestren una pendiente pronunciada, hasta llegar a una primera meseta, después de la calle Ángel Gallardo.

28 Las Juntas Vecinales son asociaciones civiles con personería jurídica municipal conformada por vecinos de los diferentes barrios de la ciudad. Si bien emergieron de forma espontánea, de la autoorganización de los habitantes para paliar restricciones en la dotación de servicios públicos, fueron institucionalizadas hacia fines de la década de 1980 por la Ordenanza 194-C-1986.

29 Ada Reiner y Mario Hott, refieren a su propio traslado, indicando la ausencia de tiempos y ordenamiento. Entrevista realizada por Paula Núñez, 25 de mayo de 2011.

30 En la denominada "Línea Sur", que abarca toda el área sur de la provincia, caracterizada fundamentalmente por el paisaje de estepa patagónica, entre la región andina y la región atlántica, incluyendo los departamentos de Pilcaniyeu, Norquinco, 25 de Mayo, Valcheta, 9 de Julio y Santo Antonio.

31 El proyecto de Centro Administrativo fue dejado de lado al tiempo que se resolvió el conflicto con Parques Nacionales por la posesión y uso del Centro Cívico, mientras que la Ciudad Judicial todavía sigue pendiente hoy, y se habla de su posible construcción en la zona este de la ciudad.

32 En 2001 hizo eclosión una profunda crisis social y económica, que venía gestándose desde 1998 en Argentina. Esta crisis se sintió con mucha fuerza en Bariloche por las particularidades de su sesgada estructura productiva, muy dependiente del turismo internacional, que había sido fuertemente desalentado por el tipo de cambio fijo del Plan de Convertibilidad.

33 Esto se reitera en las entrevistas a Noemí Guajardo y Matías Calfuquir, realizadas por Paula Núñez, 25 de mayo de 2011.

34 Este plan fue gestionado a partir de la iniciativa de los vecinos, el acuerdo del municipio y un convenio con la Fundación Madres de Plaza de Mayo (Proyecto Sueños Compartidos). La crisis institucional de esta entidad a partir del 2010 que generó un escándalo a nivel nacional motivó el traspaso del programa a la órbita municipal. La urbanización está todavía en ejecución, el proyecto está bastante avanzado, restando algunas decenas de viviendas.

35 Es muy llamativo en este sentido lo que plantea uno de los referentes de la CT en una entrevista, al relatar que la organización estuvo más de un año preparando la propuesta de organización y formándose como dirigentes, antes de salir a convocar al conjunto del barrio.

36 Matías Calfuquir, entrevista realizada por Paula Núñez, 25 de mayo de 2011. 
